\title{
Synergistic action of cinnamaldehyde with silver nanoparticles against spore-forming bacteria: a case for judicious use of silver nanoparticles for antibacterial applications
}

\author{
This article was published in the following Dove Press journal: \\ International Journal of Nanomedicine \\ 9 December 2013 \\ Number of times this article has been viewed
}

\author{
Indro Neil Ghosh ${ }^{1, *}$ \\ Supriya Deepak Patil ${ }^{1, *}$ \\ Tarun Kumar Sharma ${ }^{1,2}$ \\ Santosh Kumar Srivastava' \\ Ranjana Pathania' \\ Naveen Kumar Navani' \\ 'Department of Biotechnology, Indian \\ Institute of Technology Roorkee, \\ Roorkee, Uttarakhand, ${ }^{2}$ Center \\ for Biodesign and Diagnostics, \\ Translational Health Science and \\ Technology Institute, Gurgaon \\ Haryana, India \\ *These authors contributed equally \\ to this work
}

\begin{abstract}
Silver has long been advocated as an effective antimicrobial. However, toxicity issues with silver have led to limited use of silver in nanoform, especially for food preservation. With the aim of exploring combinatorial options that could increase the antibacterial potency of silver nanoparticles and reduce the effective dosage of silver, we evaluated the extent of synergy that a combination of silver nanoparticles and an essential oil representative (cinnamaldehyde) could offer. A battery of gram-positive and gram-negative bacterial strains was utilized for antibacterial assays, and extents of synergism were calculated from fractional inhibitory concentration indices. The activity of nanoparticles was greatly enhanced when utilized in the presence of cinnamaldehyde. We observed combinatorial effects that were strongly additive against all the bacterial strains tested, and genuine synergy was found against spore forming Bacillus cereus and Clostridium perfringens - bacterial strains associated with release of cytotoxins in contaminated food and known for their persistence. Bacterial kill curve analysis revealed a very fast bactericidal action when a combination of two agents was used. The electron and atomic force microscopy also revealed extensive damage to the bacterial cell envelop in the presence of both agents. We also performed hemolysis assays to investigate and approximate the extent of toxicity exhibited by the two agents, and observed no adverse effect at the concentrations required for synergy. This study shows that safe levels of silver in nanoform in combination with essential oil component cinnamaldehyde can be effectively used for controlling the sporeforming bacterial species.
\end{abstract}

Keywords: antibacterial activity, bacterial food spoilage, erythrocyte toxicity, essential oil, in vitro, synergy, toxin producing spore-forming bacteria

\section{Introduction}

Presence of undesirable bacterial species in food is associated with a variety of food poisoning and similar medical conditions. Seventy percent of the enteric infections are attributable to food contamination. ${ }^{1}$ Among commonly found bacterial species in food items, spore forming bacteria are notorious due to their ability to produce spores and survive in the typical heat and other treatments used to inhibit undesirable bacterial growth. Once the favorable conditions return, the treatments ramify in proliferation of vegetative cells of spore-formers in absence of competition from other non-spore forming bacteria. This leads to toxin formation and food spoilage causing food poisoning. ${ }^{2}$ Bacillus cereus and Clostridium perfringens are gram-positive spore forming, toxin producing bacterial species ${ }^{3}$ typically responsible for food poisoning outbreaks due
Correspondence: Naveen Kumar Navani Department of Biotechnology, Indian Institute of Technology Roorkee, Roorkee, District - Haridwar, Uttarakhand, India 247667

Tel +9| 976 |30 597|

Fax +911332286151

Email navnifbs@iitr.ernet.in, naveenbiochem@gmail.com 
to toxins released by the vegetative cells. ${ }^{4}$ B. cereus is a recognized human pathogen that releases cytotoxins and causes local or systemic infections such as endophthalmitis and septicemia mostly associated with consumption of contaminated dairy food. ${ }^{3}$ C. perfringens produces enterotoxin and has been associated with improper cooking and storage of meat products. The affected individual can suffer from bacteremia and gas gangrene. These two spore-forming bacterial species represent most persistent food spoilage causes worldwide. Due to their high economic and health importance, several approaches are being explored for the mitigation of these bacterial species.

Silver is known to be a potent inhibitor of bacterial growth and colonization. As a bactericide, silver has been used in pharmaceutical ointments, food storage, packaging, and processing. Although silver in various chemical forms has toxicity to microorganisms, silver nanoparticles (AgNPs) have gained increased interest due to their strong antimicrobial activities. ${ }^{5}$ It has been found that AgNPs have antibacterial effects at low concentrations, and that the antibacterial properties are associated with the particle surface area. ${ }^{6}$ Due to the multifaceted mode of action of AgNPs, bacteria are unable to develop genetic resistance against it. ${ }^{7}$ This characteristic ensures that silver will remain a very useful bactericide. The exact mode of action of silver ions and AgNPs is unknown, but they have been demonstrated to accumulate at both the outer and inner membranes of bacteria leading to their destabilization. ${ }^{8}$ AgNPs have also been shown to damage the proton motive force across the plasma membrane, leading to decreased levels of intracellular adenosine triphosphate. ${ }^{9}$ Precise mechanism, toxic dosage and the extent of the toxicity that AgNPs pose to humans are still under investigation. However, chronic ingestion of silver in higher quantities has been implicated in a variety of conditions, argyria being the best known. ${ }^{10}$

Another category of food preservatives, the essential oils derived from spices, also possesses antimicrobial activities against both gram-positive and gram-negative bacteria. ${ }^{11}$ Substituted aromatic derivatives such as cinnamaldehyde, eugenol, and carvacrol present in these oils have been isolated as the active antimicrobial components. ${ }^{12}$

Cinnamaldehyde has been identified and utilized as a nontoxic, food grade antimicrobial agent. It is generally regarded as safe by the US Food and Drug Administration (FDA). ${ }^{13}$ Only high concentrations for prolonged exposures have been shown to cause detrimental physiological changes in mammals. ${ }^{14}$ Cinnamaldehyde, along with other spice oils, can be expected to be present in a variety of cinnamon containing foods and other edible preparations. ${ }^{15}$ Combinations of different spice oils have been shown to reduce the required concentrations sufficiently enough to decrease their aromas to significantly low levels, so as to make them viable useeverywhere preservatives. ${ }^{16}$

While the mechanisms of action of these essential oil components have not been accurately elucidated, some studies have indicated that their mechanisms of action are their interactions with the bacterial cell surface ${ }^{17}$ and inhibition of energy metabolism. ${ }^{11}$ Recently, chemical genetic approaches have been used to understand the mode of action of these essential oils. ${ }^{18,19}$ Most of the essential oil components studied probably share some commonality in their antibacterial mode of action. Incidences of significant resistance against cinnamaldehyde (and other spice oils) have not been reported; on the other hand, bacterial strains that have developed antibiotic resistance have been shown to be susceptible to these oils. ${ }^{20}$ To resolve the problem of high concentrations at which both AgNPs and spice derived essential oil components like cinnamaldehyde must be used to be effective, one suggestion is that these components be utilized together, along with other agents, so as to act synergistically. The fact that both agents engage in surface disruption and energy balance disruption would advocate their potential for augmenting each other's antibacterial effects. Such systems can also be expected to present insurmountable barriers to the growth of pathogens. We investigated the effects of utilizing an essential oil derivative along with AgNPs.

We tested ten bacterial strains - five gram-negative (Escherichia coli, Pseudomonas aeruginosa, Enterobacter sakazakii, Salmonella typhi, and a multiple antibiotic resistant strain of Vibrio fluvialis) and five gram-positive strains (B. cereus, Micrococcus luteus, Clostridium perfringens, Listeria monocytogenes, and Staphylococcus aureus) - to investigate the relative activities of cinnamaldehyde and AgNPs before observing the extents of synergy seen between the two antimicrobial preparations. The prime objective of these experiments was to investigate if the two worked synergistically at all, and to provide indications toward the extent to which the utility of AgNPs as bactericidal agents would benefit by from presence of a representative essential spice oil.

\section{Materials and methods Materials}

Silver nitrate and dimethyl sulfoxide (DMSO) were obtained from Merck KGaA (Darmstadt, Germany). Sodium citrate, buffers, bacterial growth medium, trans-cinnamaldehyde (3-phenyl-2-propenal), and Triton ${ }^{\circledR}$ X-100 were procured 
from Sigma-Aldrich (St Louis, MO, USA). All plasticware96-well plates - were procured from Corning Inc., (Corning, NY, USA). Incubation for antibacterial assays was done in a shaker-incubator from Kuhner AG (Basel, Switzerland) with additional option to main humidity to take care of the edge-effects. The optical density of the microbial cells in the 96-well plates was read using Spectra-Max plus spectrophotometer (Molecular Devices LLC, Sunnyvale, CA, USA). All the standard bacterial strains used in this study were confirmed till species level by $16 \mathrm{~S}$ rRNA sequencing before the start of the study. Vibrio fluvialis 15318 is a multiple drug resistant clinical isolate that is resistant to eleven antibiotics. ${ }^{21}$ For media, buffer preparation, and dilutions, ultra-pure water was made using the Elix $^{\circledR}$ water purification system from Merck Millipore (Billerica, MA, USA).

\section{Synthesis and characterization of silver nanoparticles}

Citrate capped AgNPs were synthesized using a previously published method. ${ }^{22}$ The prepared silver nanoparticle suspension was then dialyzed through a $10 \mathrm{kDa}$ membrane in MilliQ water (Merck Millipore) overnight. An ultraviolet-visible spectrophotometer (Varian, Inc., Palo Alto, CA, USA) was utilized to characterize the nanoparticle suspension. Zeta potential was measured using a Zeta plus/Zeta potential analyzer (Malvern Instruments, Malvern, UK). The silver in the nanoparticles suspension was quantified by utilizing an atomic absorption spectrophotometer. The surface morphology of nanoparticles along with elemental analysis were obtained on a FEI-Quanta 200F field emission scanning electron microscope (SEM) coupled with an energy dispersive $\mathrm{X}$-ray analysis facility by applying an acceleration voltage of $20 \mathrm{kV}$. SEM analysis of the nanoparticles was carried out by spreading out a drop of AgNPs solution on a glass slide followed by gold plating. In order to get further insight in to the morphology of the nanoparticles, transmission electron microscopy (TEM) was performed, which also allowed us to assess the particle sizes. Samples for TEM were prepared on carbon coated copper grids, and examined with an accelerating voltage of $200 \mathrm{kV}$ on a JEM-2100F (JEOL, Tokyo, Japan).

\section{Bacterial strain growth}

Most of the bacterial strains were obtained from the laboratory's strain database. Multiple drug resistant clinical isolate V.fuvialis 15318 is a kind gift from Professor Amit Ghosh of National Institute of Cholera and Enteric Diseases, Kolkata, India. All bacterial strains were cultured and maintained in
Luria Bertani broth or Luria Bertani agar (HiMedia Laboratories, Mumbai, India). The antimicrobial assays with AgNPs were exclusively carried out in Mueller-Hinton (MH) broth. The cells were grown at $37^{\circ} \mathrm{C}$ with shaking at $200 \mathrm{rpm}$ (for aerobic strains only) and $85 \%$ humidity.

\section{Antimicrobial assays}

The susceptibility of the microbial cells to the preparations of AgNPs and to cinnamaldehyde was determined by micro broth dilution assays of the Clinical and Laboratory Standards Institute, ${ }^{23}$ with inoculations of approximately $10^{5}$ colony forming units per milliliter $(\mathrm{CFU} / \mathrm{mL})$ of the respective organisms. The nanoparticles were resuspended by bath sonication before use in the assays. The cinnamaldehyde was prepared as a 1:10 diluted stock in DMSO, subsequently diluted by water, and emulsified by sonication. The cellular growth was observed after 10 hours using a Spectramax Plus plate reader (Molecular Devices LLC, Sunnyvale, CA, USA), and any growth above $10 \%$ of the average final optical density of the positive control wells (lacking any antimicrobial agent) was considered as uninhibited growth.

To evaluate synergism between AgNPs and cinnamaldehyde, a two dimensional micro dilution method was utilized, which was formulated as a modification of the methodology utilized for one dimensional assays. To test and optimize synergistic combinations, serial dilution of the two agents was used in a 96-well plate starting from twice the minimum inhibitory concentration (MIC) of the individual antimicrobial agents. For example, 1,225 ng/mL of AgNPs and $0.526 \mathrm{mg} / \mathrm{mL}$ of cinnamaldehyde were used for $E$. coli followed by a serial dilution from there on. Based on the geometry of the 96-well plate used, eight or 12 serial dilutions were tested. Thus, $12 \times$ eight combinations of both agents were tested to arrive at synergy values.

The presence and extent of synergism was evaluated by calculating the fractional inhibitory concentration index ${ }^{24}$ as the combined antibiotic effect of agents A and B (where $\mathrm{A}$ is AgNPs and B is cinnamaldehyde) and was calculated as follows:

The fractional inhibitory concentration (FIC) index $=\mathrm{MIC}(\mathrm{A}$ in combination with $\mathrm{B}) / \mathrm{MIC}(\mathrm{A}$ alone $)$ $+\mathrm{MIC}(\mathrm{B}$ in combination with $\mathrm{A}) / \mathrm{MIC}$ (B alone).

"Synergy" was defined when FIC index was less than or equal to 0.5 , while "additive" was that in which the FIC index was greater than 0.5 and less than or equal to 1.0 , whereas "indifferent" was when the FIC index was greater than 1.0. ${ }^{25}$ 


\section{In vitro time-kill kinetics}

Time-kill curve methods were used to evaluate the synergistic activities of AgNPs alone or in combination with cinnamaldehyde against $B$. cereus and $C$. perfringens. B. cereus was grown under aerobic conditions $\left(37^{\circ} \mathrm{C}\right.$ with shaking at $200 \mathrm{rpm}$ ), whereas C. perfringens was grown at $37^{\circ} \mathrm{C}$ under static conditions in $\mathrm{MH}$ broth. An overnight broth culture was diluted in $\mathrm{MH}$ broth to obtain a starting inoculum of about $1 \times 10^{5} \mathrm{CFU} / \mathrm{mL}$. Cinnamaldehyde and AgNPs alone or in combination were added to the bacterial broth at half the concentration of the synergy values (AgNPs at $153.15 \mathrm{ng} / \mathrm{mL}$ plus cinnamaldehyde at $0.04 \mathrm{mg} / \mathrm{mL}$ for $B$. cereus and AgNPs at $76.5 \mathrm{ng} / \mathrm{mL}$ plus cinnamaldehyde at $0.08 \mathrm{mg} / \mathrm{mL}$ for C. perfringens). $100 \mu \mathrm{L}$ aliquots of broth were taken after $0,30,60,90,120,150$ and 180 minutes of incubation. Each aliquot was serially diluted and plated onto $\mathrm{MH}$ agar plates in duplicates and incubated overnight at $37^{\circ} \mathrm{C}$. The number of colony forming units was counted and $\mathrm{CFU} / \mathrm{mL}$ was determined. The values were plotted to obtain the killkinetics. In this case, synergy was defined as a decrease in the viable cell count by at least $2 \times \log _{10}$ of that obtained with the most effective agent used alone. Inbuilt features of Excel in Microsoft office package (Microsoft Corporation, Redmond, WA, USA) were used for statistical analysis.

\section{Bacterial cell microscopy}

SEM and atomic force microscopy (AFM) of two bacterial strains (B. cereus and S. aureus) were carried out to observe changes in surface morphologies of the bacterial cells after treatments with subinhibitory concentrations of the antibacterial agents. The bacterial samples were prepared by dehydration using stepwise treatment in 30\%-70\% ethanol, followed by their deposition on glass slides. The samples for SEM were precoated with gold film. AFM was performed using an NTEGRA-MDT atomic microscope (NT-MDT, Moscow, Russia). For AFM sample preparation, drop coating method was used; ${ }^{26}$ a drop of bacterial sample (treated or untreated) was spread on a glass slide, dried at room temperature and visualized under the atomic force microscope.

\section{Hemolysis assays}

Cytotoxicity of the AgNPs and cinnamaldehyde was determined with relation to lysis of the red blood cells (hemolysis). Hemolysis assays were performed to assess the extent of the benefit, in terms of reduced toxicity effects, from the synergistic concentrations of two agents. For this, the standard methodology (ASTM E2524-08) ${ }^{27}$ with some modifications was utilized. Blood was taken in sterile vacutainers from volunteers in the pathology lab of the institute hospital, as per permission from the ethical board. Erythrocytes were separated from blood and suspended in a $172 \mathrm{mM}$ Tris(hydroxymethyl)aminomethane hydrochloride buffer at $\mathrm{pH}$ 7.6. The hemolysis assays were conducted in $2 \mathrm{~mL}$ reactions with $0.125 \%$ final hematocrit and a buffer containing the set concentration of the agents. AgNPs were tested at concentrations from 7,000 to $50 \mathrm{ng} / \mathrm{mL}$ and cinnamaldehyde concentrations ranging from 1.5 to $0.05 \mathrm{mg} / \mathrm{mL}$. $0.1 \%$ Triton ${ }^{\circledR}$ X-100 was utilized as the positive control as final concentration, which we set as a $100 \%$ hemolysis standard. A $10 \%$ DMSO solution in the buffer was set as the negative control. The incubated solutions were centrifuged at $1,500 \times g$ after 1 hour and supernatant was collected and analyzed by ultraviolet-visible spectroscopy $(\lambda \max =576 \mathrm{~nm})$ for released hemoglobin. The percentage hemolysis was calculated from the fraction of hemoglobin released into the medium, compared to the positive control, assessed by observing the absorbance at $576 \mathrm{~nm}$ as:

$$
\begin{aligned}
\% \text { hemolysis }= & \left\{\left(\mathrm{Abs}_{\text {test }}-\mathrm{Abs}_{\mathrm{DMSO}}\right) /\left(\mathrm{Abs}_{100 \%}-\mathrm{Abs}_{\mathrm{DMSO}}\right)\right\} \\
& \times 100
\end{aligned}
$$

where $\mathrm{Abs}_{\text {test }}$ is the absorbance of the supernatant from samples incubated with the AgNPs, cinnamaldehyde, or combination of two agents, $\mathrm{Abs}_{\text {DMSO }}$ is the absorbance of the supernatant from controls (10\% DMSO), and $\mathrm{Abs}_{100 \%}$ is the absorbance of the supernatant of controls incubated in the presence of $0.1 \%$ Triton ${ }^{\circledR} \mathrm{X}-100$, which causes complete lysis of erythrocytes.

\section{Results and discussion Characterization of silver nanoparticles}

The resultant nanoparticle suspension gave a sharp surface plasmon band at $415 \mathrm{~nm}$ (Figure 1) which is an expected characteristic. Zeta potential was $-23 \mathrm{mV}$ which suggested that these nanoparticles were stable. Under TEM, the nanoparticles appeared as mostly monodispersed and spherical with mean diameter of 25-40 nm (Figure 2). Similar observations were recorded by SEM (Figure 3A). Energy dispersive $\mathrm{X}$-ray analysis revealed a strong signal in the silver region $(3 \mathrm{keV})$ and confirmed the formation of AgNPs (Figure 3B).

\section{Antimicrobial activity of cinnamaldehyde and AgNPs}

There was a range across which the MICs of both the nanoparticles and cinnamaldehyde varied for the ten bacterial 


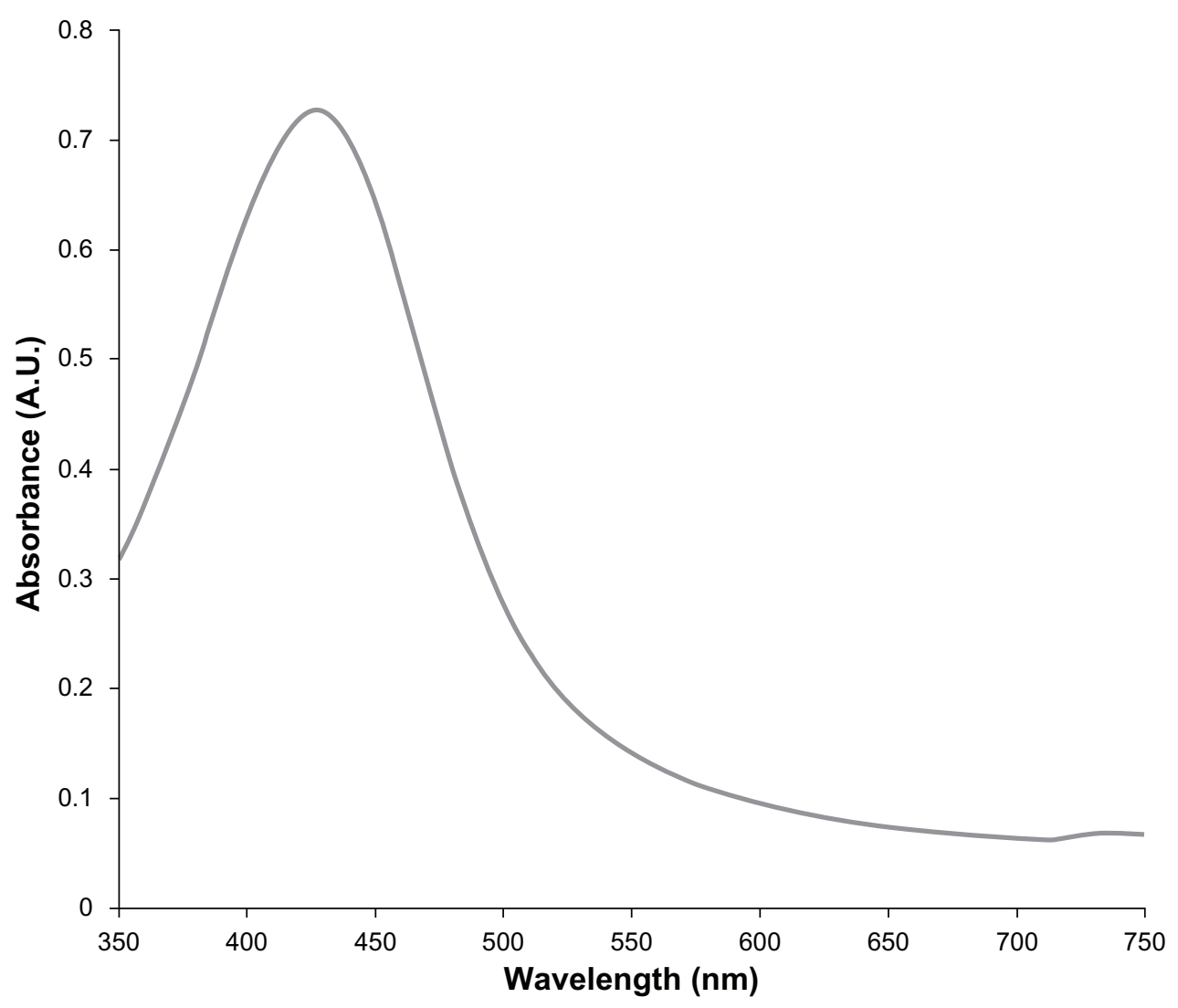

Figure I Absorption spectrum of silver nanoparticles showing surface plasmon resonance bend at $415 \mathrm{~nm}$.

strains tested in this study (Table 1). Cinnamaldehyde inhibited gram-positive and gram-negative strains to similar extents. MIC values for cinnamaldehyde ranged from $0.065 \mathrm{mg} / \mathrm{mL}$ for $C$. perfringens to $1.313 \mathrm{mg} / \mathrm{mL}$ for M. luteus and $P$. aeruginosa. The range of inhibitory concentrations

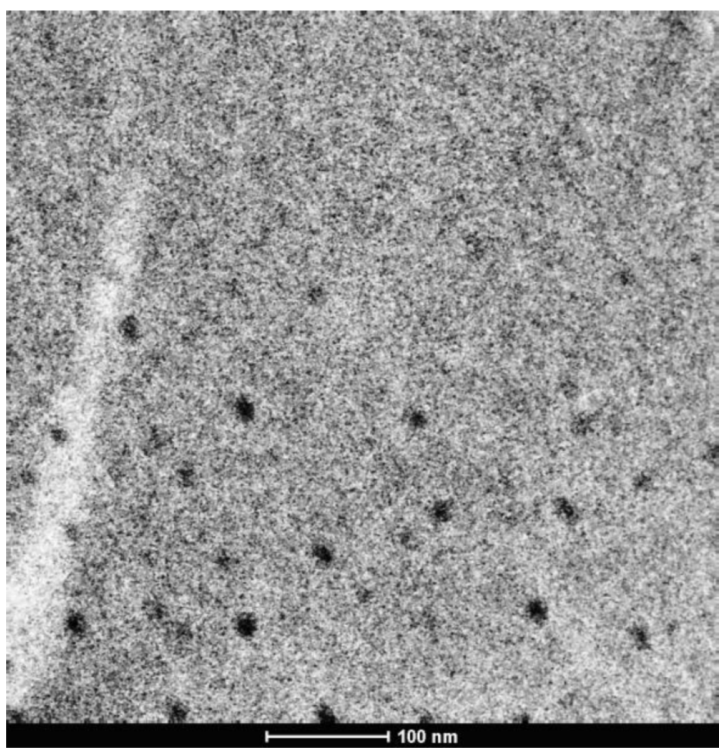

Figure 2 Transmission electron micrograph of silver nanoparticles. also agreed with reported values in the literature. ${ }^{28}$ The synthesized AgNPs also showed an inhibitory action that appeared to be irrespective of the gram-positive or gramnegative nature of the bacterial species. The inhibitory concentrations of AgNPs varied in the $0.6-6 \mu \mathrm{g} / \mathrm{mL}$ range for the organisms. When tested alone, cinnamaldehyde was most effective against $C$. perfringens whereas AgNPs showed antibacterial against $E$. coli, $C$. perfringens, and $E$. sakazakii under lowest concentration.

\section{Evaluation of synergistic action}

When tested together, the two antimicrobials worked in an effective manner and the combination showed at least an additive or near-synergistic effect for all the strains used. The combination exhibited a genuine synergy for $B$. cereus and $C$. perfringens (Table 1). At most of the concentrations, the percent inhibition of the combination was also higher than the sum of individual inhibition extents (Figure 4). For C. perfringens, the inhibitory concentration of AgNPs was reduced from an MIC of $612.5 \mathrm{ng} / \mathrm{mL}$ alone to $153.1 \mathrm{ng} / \mathrm{mL}$ at synergy point, whereas, for cinnamaldehyde, MIC was reduced from $0.065 \mathrm{mg} / \mathrm{mL}$ alone to $0.016 \mathrm{mg} / \mathrm{mL}$ in combination at synergy point. For B. cereus, the inhibitory concentration of 

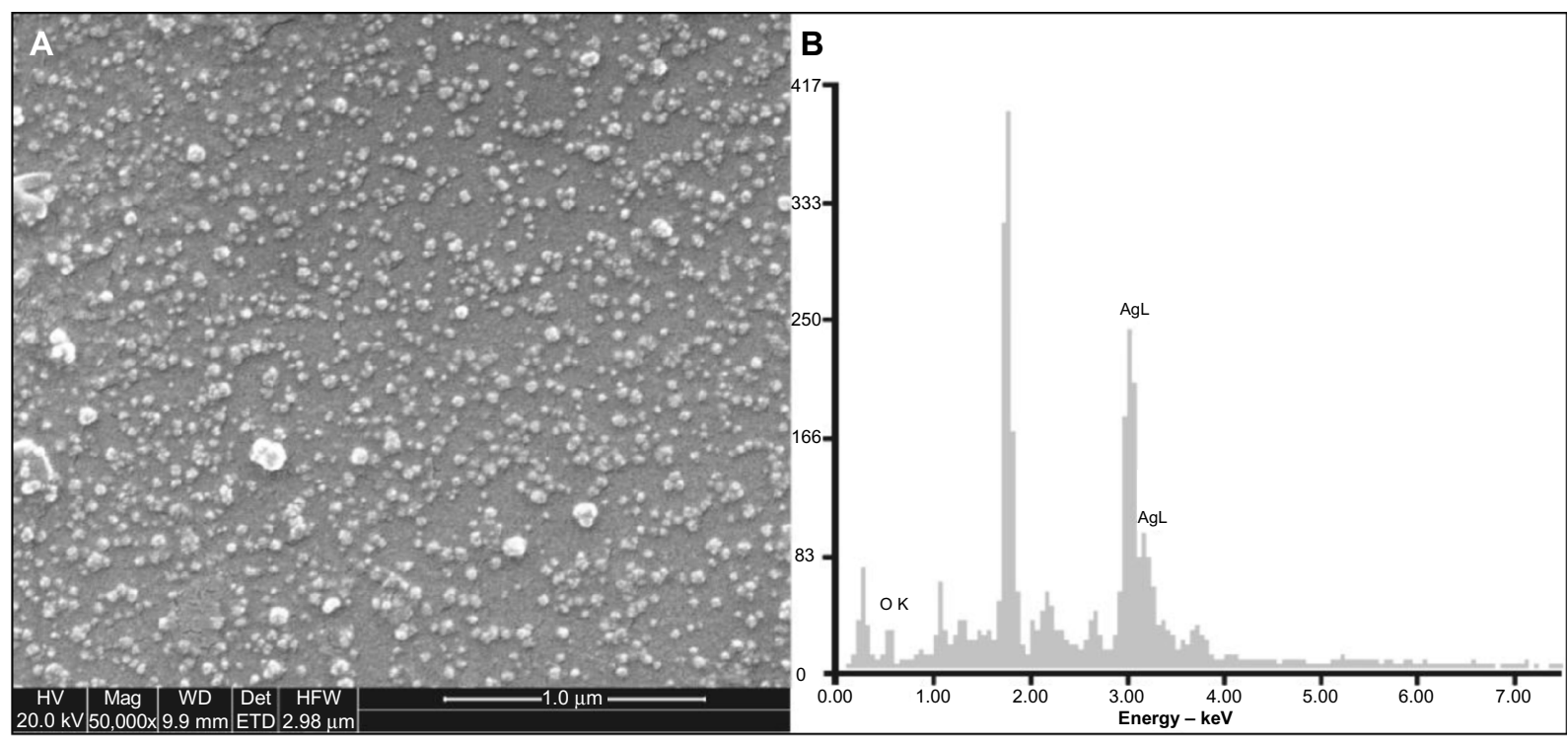

Figure 3 FE-SEM image (A) and EDAX (B) profile of the silver nanoparticles.

Abbreviations: HV, accelerating voltage; Mag, magnification; WD, working distance; Det, detector; HFW, horizontal field width; FE-SEM, field emission scanning electron microscope; EDAX, energy dispersive $\mathrm{X}$-ray spectroscopy; keV, kilo electron volt

AgNPs was reduced from an MIC of $1,225 \mathrm{ng} / \mathrm{mL}$ alone to $306.3 \mathrm{ng} / \mathrm{mL}$ at synergy point, whereas, for cinnamaldehyde, MIC was reduced from $0.328 \mathrm{mg} / \mathrm{mL}$ alone to $0.082 \mathrm{mg} / \mathrm{mL}$ in combination at synergy point. The synergistic inhibitory effect was observed as soon as the two agents were added in combination. To confirm the synergistic effect of cinnamaldehyde with AgNPs and to assess the kinetics of killing effect, an in vitro time-kill kinetic experiment was carried out with both B. cereus and C. perfringens (Figure 5A and B). Initial experiments with concentration of two agents at synergy points showed that the combination was bactericidal within a minute of the start of the treatment (no viable cells detected within one minute of the treatment). So as to get an idea of the inhibition kinetics, it was decided to conduct the experiment at half of the concentration of the two agents at synergy points for both spore-forming bacteria. The kill curves (Figure 5A and B) revealed that the AgNPs in isolation had a more pronounced effect on C. perfringens as compared to B. cereus. However, in combination, both agents showed extensive inhibition of both spore-forming bacteria, reducing them to two logs even at half the concentration of synergy points.

\section{SEM and AFM imaging of treated bacterial cells}

The effect of various treatments on bacterial cells are shown in Figure 6A to 6D (for B. cereus) and Figure 6E to $6 \mathrm{H}$ (for $S$. aureus). B. cereus and $S$. aureus cells showed normal morphologies without any treatment (Figure 6A, E and Figure 7A, E).

Table I Antimicrobial susceptibilities to silver nanoparticles and cinnamaldehyde in terms of $\mathrm{MIC}$ and $\mathrm{FICl}$

\begin{tabular}{|c|c|c|c|c|c|}
\hline \multirow[t]{2}{*}{ Bacterial strain } & \multicolumn{2}{|l|}{ MIC } & \multicolumn{2}{|c|}{ Conditions at best synergy points } & \multirow[t]{2}{*}{$\mathbf{F I C l}$} \\
\hline & $\begin{array}{l}\text { AgNPs } \\
\text { (ng/mL) }\end{array}$ & $\begin{array}{l}\text { Cinnamaldehyde } \\
(\mathrm{mg} / \mathrm{mL})\end{array}$ & $\begin{array}{l}\text { AgNPs } \\
\text { (ng/mL) }\end{array}$ & $\begin{array}{l}\text { Cinnamaldehyde } \\
(\mathrm{mg} / \mathrm{mL})\end{array}$ & \\
\hline \multicolumn{6}{|c|}{ Non-spore forming bacteria } \\
\hline Escherichia coli & 612.5 & 0.263 & 38.3 & 0.131 & 0.531 \\
\hline Pseudomonas aeruginosa & $6,125.0$ & 1.313 & 382.8 & 0.656 & 0.562 \\
\hline Enterobacter sakazakii & 612.5 & 0.263 & 76.6 & 0.131 & 0.562 \\
\hline Salmonella typhi & $3,062.5$ & 0.131 & 191.4 & 0.065 & 0.531 \\
\hline Staphylococcus aureus & $3,062.5$ & 0.328 & 191.4 & 0.164 & 0.531 \\
\hline Vibrio fluvialis (MDR) & $6,125.0$ & 0.656 & 191.4 & 0.328 & 0.516 \\
\hline Micrococcus luteus & $6,125.0$ & 1.313 & 191.4 & 0.656 & 0.516 \\
\hline Listeria monocytogenes & $6,125.0$ & 0.263 & 382.8 & 0.131 & 0.531 \\
\hline \multicolumn{6}{|c|}{ Spore forming bacteria } \\
\hline Clostridium perfringens & 612.5 & 0.065 & 153.1 & 0.016 & 0.500 \\
\hline Bacillus cereus & $1,225.0$ & 0.328 & 306.3 & 0.082 & 0.500 \\
\hline
\end{tabular}

Abbreviations: AgNPs, silver nanoparticles; FICl, fractional inhibitory concentration index; MDR, multiple drug resistant; MIC, minimum inhibitory concentration. 


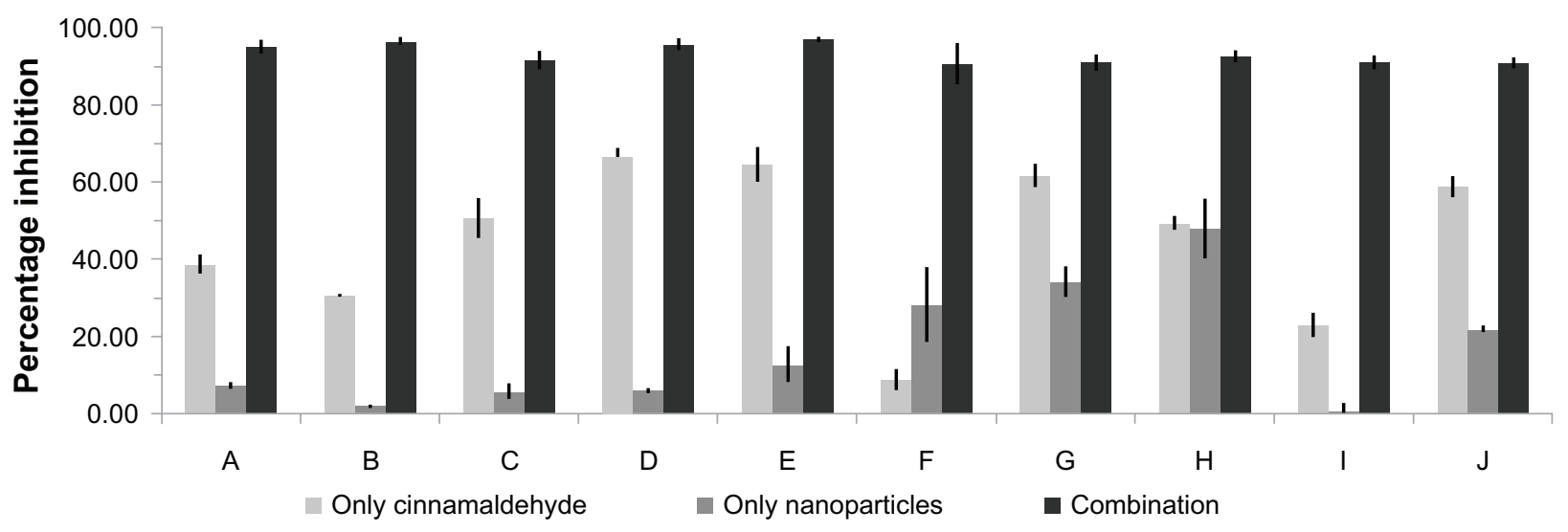

Figure 4 Increase in extent of bacterial growth inhibition by combination of AgNPs and cinnamaldehyde.

Notes: The concentrations of the AgNPs and cinnamaldehyde used are from respective synergy values calculated for individual bacterial species. (A) Escherichia coli, (B) Pseudomonas aeruginosa, (C) Enterobacter sakazakii, (D) Salmonella typhi, (E) Vibrio fluvialis, (F) Clostridium perfringens, (G) Listeria monocytogenes, (H) Micrococcus luteus, (I) Bacillus cereus, (J) Staphylococcus aureus.

Abbreviation: AgNPs, silver nanoparticles.

Upon treatment with AgNPs, some perturbations were visible on the surface of both cell types (Figure 6B, F and Figure 7B, F). Cinnamaldehyde showed slightly less noticeable surface disruption effects. However, in combination, both agents showed a more pronounced effect (Figure 6D, H and Figure 7D, H) as the cells underwent considerable morphological alterations in comparison with the control (no agent added) or when added alone. The cell structures under SEM and AFM appeared flaccid in the presence of both agents whereas the control cells appeared as whole. For both $B$. cereus and $S$. aureus there was indication of extensive damage to the cell wall, which likely led to leakage of the cytoplasm resulting in wilting of the cells in the presence of both agents. In particular, AFM highlighted the disruption in the surface of B. cereus and $S$. aureus cells (Figure 7D and $\mathrm{H}$ ).

\section{Hemolysis assays}

No hemolysis was observed for AgNPs at and below the concentrations of $2,000 \mathrm{ng} / \mathrm{mL}$, while higher concentrations showed hemolysis after prolonged exposures of 3 hours. Cinnamaldehyde showed no hemolysis whatsoever for all the concentrations $(<1.5 \mathrm{mg} / \mathrm{mL})$ tested, even after prolonged exposures. The positive controls showed complete destruction of most of the erythrocytes which was evident from the absence of a colored pellet, while the negative controls were negligibly higher in hemoglobin concentrations as compared to the buffer blank. At the concentration of synergy points for B. cereus and $C$. perfringens, there was no significant lysis of the erythrocytes ( $0.89 \%$ for B. cereus and $2.7 \%$ for C. perfringens) even after 1 hour of exposure, leading to the observation that, under synergy point concentrations, the combination of AgNPs and cinnamaldehyde does not show any toxic effect to the erythrocytes and can be regarded as hemocompatible.
In this study, the combined antibacterial effect of AgNPs and cinnamaldehyde on several bacterial food pathogens has been investigated. Cinnamaldehyde was the essential oil component of choice as studies have reported cinnamon oil's potent broad spectrum antimicrobial activities, including gram-positive bacteria, gram-negative bacteria, and pathogenic yeast species..$^{29,30}$ In the present investigation, the toxicity of both agents on human erythrocytes has also been studied to gain an insight into the width of the window between toxic concentrations and concentrations effective as antimicrobials.

It was clear that the combination was highly effective against the bacterial cells; notably, synergy was observed for inhibition of spore formers. The entire battery of strains was inhibited by concentrations of the agents that were not even close to causing hemolysis of the human erythrocytes (Table 1). A multiple drug resistant strain of $V$. fluvialis was also inhibited to a greater extent in the presence of both agents. SEM and AFM showed that the combination of the agents exerted an intensity of surface disruption that was not observed when the same concentration of the two agents was used in isolation. We hypothesize that this may be attributed to an actual synergistic action between the surface disruption effects that the two agents have been previously shown to exert. ${ }^{8,17}$ In fact, the morphology of $S$. aureus treated by the combination (Figure 7H) is reminiscent of what can be observed when only treated by nanoparticles, but in higher concentrations. ${ }^{31}$

To prevent the chronic accumulation of silver in the body, the maximum concentration of silver ions as a contaminant in drinking water has been established at $100 \mathrm{ng} / \mathrm{mL}$ by the World Health Organization. ${ }^{32}$ The amount of silver described as orally consumable by the Environment Protection Agency, 

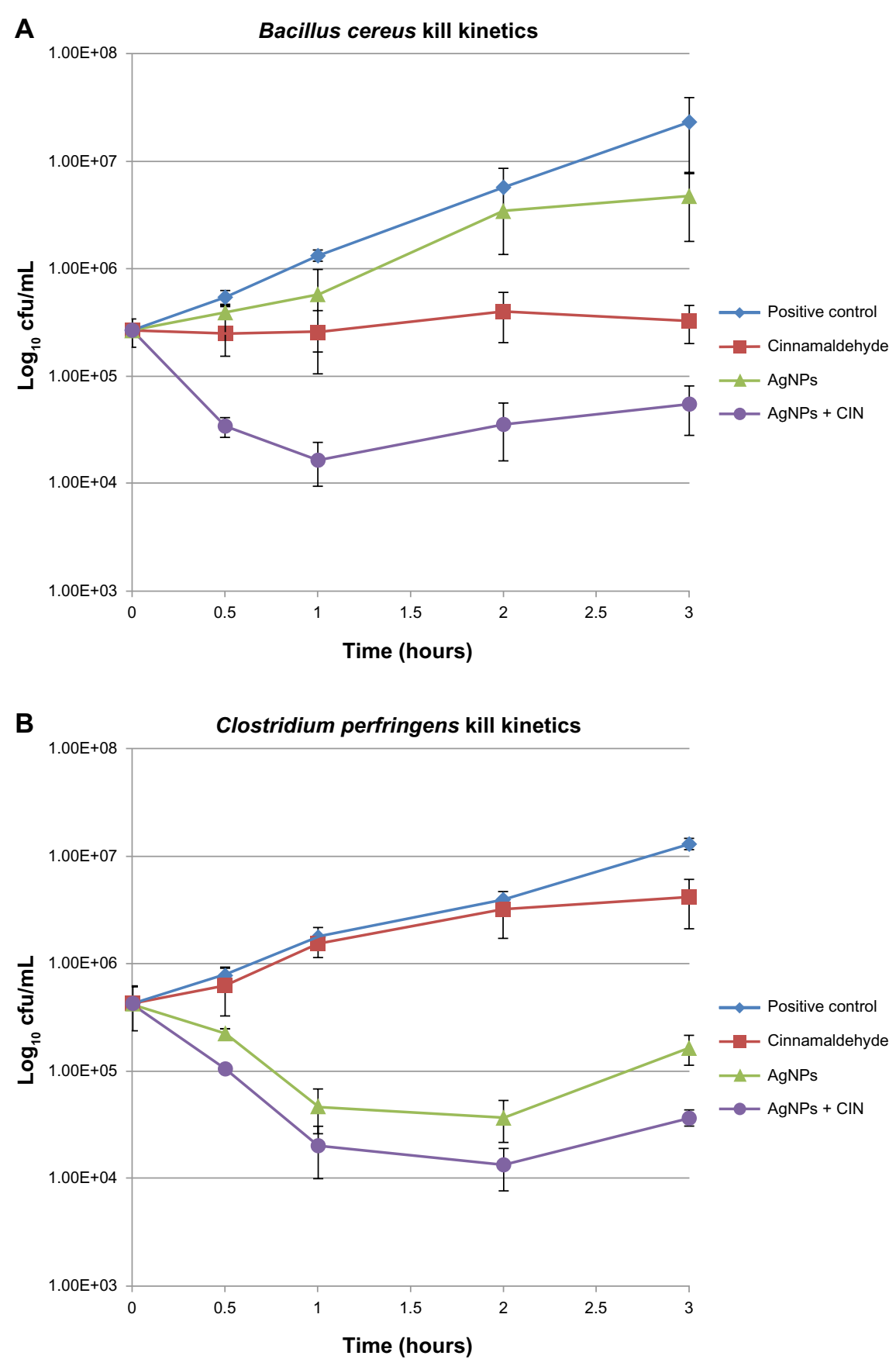

Figure $\mathbf{5}$ In vitro time-kill curves of SNP and CIN alone and in combination against Bacillus cereus (A) and Clostridium perfringens (B) at half of MIC at synergy point values. Note: Results are expressed as $\log _{10} \mathrm{CFU} / \mathrm{mL}$.

Abbreviations: CFU, colony forming units; CIN, cinnamaldehyde; MIC, minimum inhibitory concentration; AgNPs, silver nanoparticles.

USA is $5 \mu \mathrm{g} / \mathrm{kg} /$ day. ${ }^{33}$ It is encouraging to note that the concentrations of AgNPs active against bacteria have been brought close to the reference doses for humans that can be chronically ingested. Toxicity of nanoform of silver to higher forms of life has been a subject of various studies. ${ }^{34,35} \mathrm{In}$ an investigation to develop silver in nanoform as a topical agent, it was found that AgNPs did not affect the morphology of mammalian cells up to a concentration of
6,500 ng/mL. ${ }^{34,35}$ A detailed follow-up of the AgNP effect on various cellular parameters also revealed that IC50 of AgNPs on two different mammalian cell lines was above a concentration of $10,000 \mathrm{ng} / \mathrm{mL}$. Further, in vitro toxicity studies concluded that, at the antimicrobial concentration of 1,500-6,500 ng/mL, AgNPs are safe to the mammalian cell lines. ${ }^{34}$ It has also been reported that DNA damage to the mammalian fibroblast cells is only observable beyond 

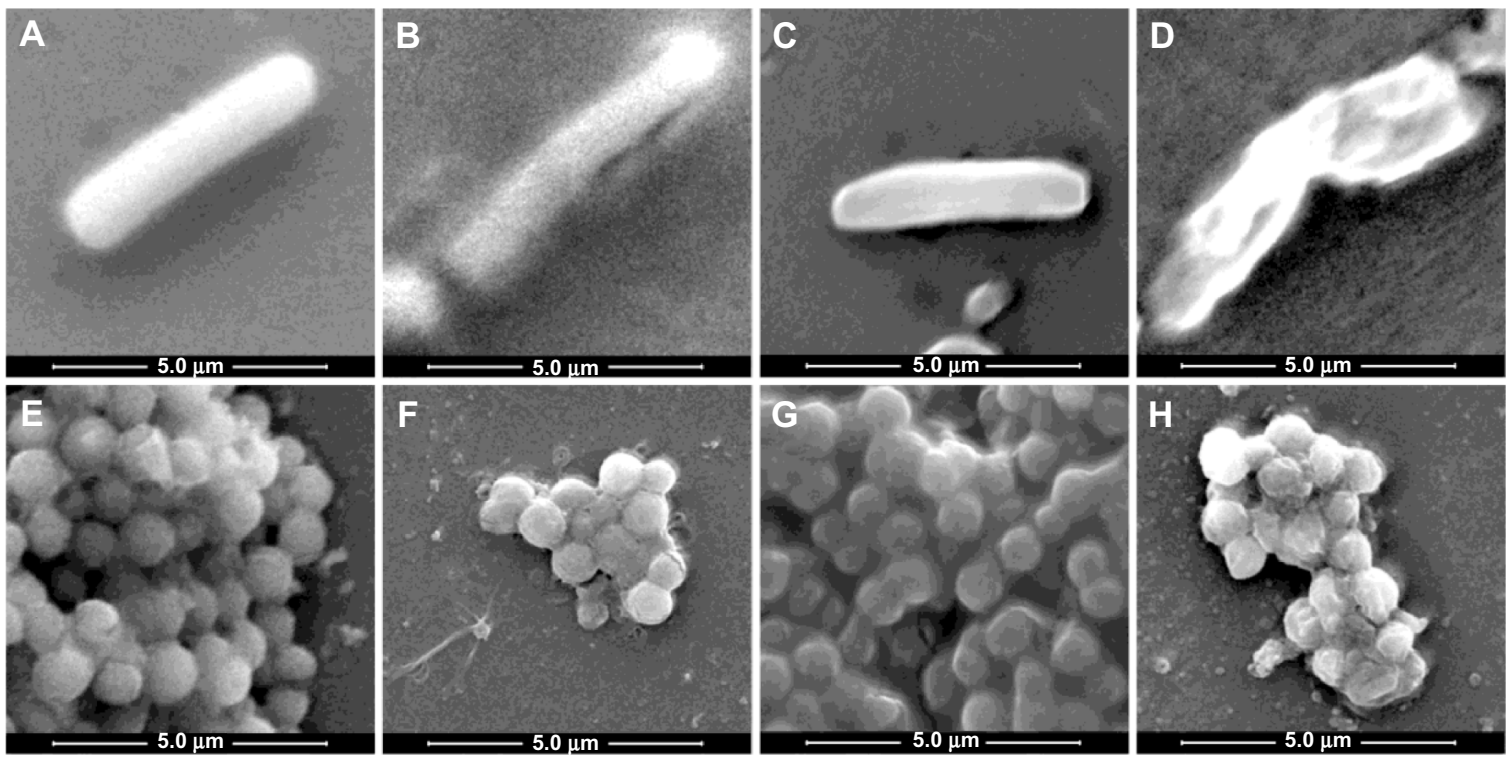

Figure 6 Bacterial morphologies observed by SEM, when treated by SUB-MIC concentrations of the two agents.

Notes: (A-D) Bacillus cereus, (E-H) Staphylococcus aureus. (A and E) No treatment with any agent, (B and F) treated with AgNPs, (C and G) treated with cinnamaldehyde, $(\mathbf{D}$ and $\mathbf{H})$ treated with slightly reduced concentrations of both agents from best synergy combination.

Abbreviations: AgNPs, silver nanoparticles; SEM, scanning electron microscopy; SUB-MIC, sub-minimum inhibitory concentration.

25,000 $\mathrm{ng} / \mathrm{mL}$ of AgNP concentration. ${ }^{35}$ In light of these recent toxicity studies, the proposed levels of $\mathrm{AgNP}$ under synergy points in the present investigation are within safe limits. The toxicity studies on erythrocytes also corroborate the safety limits of silver as found by other groups. ${ }^{34,35}$ In the present study, the range of effective AgNP concentration has been brought down from around $6,000 \mathrm{ng} / \mathrm{mL}$ (when used alone) to a range between 400 and $500 \mathrm{ng} / \mathrm{mL}$ (in combination with cinnamaldehyde).

AgNPs and cinnamaldehyde separately have already been shown to act on a wide variety of bacteria including antibiotic resistant organisms. ${ }^{9,17}$ Combined with the possibility that
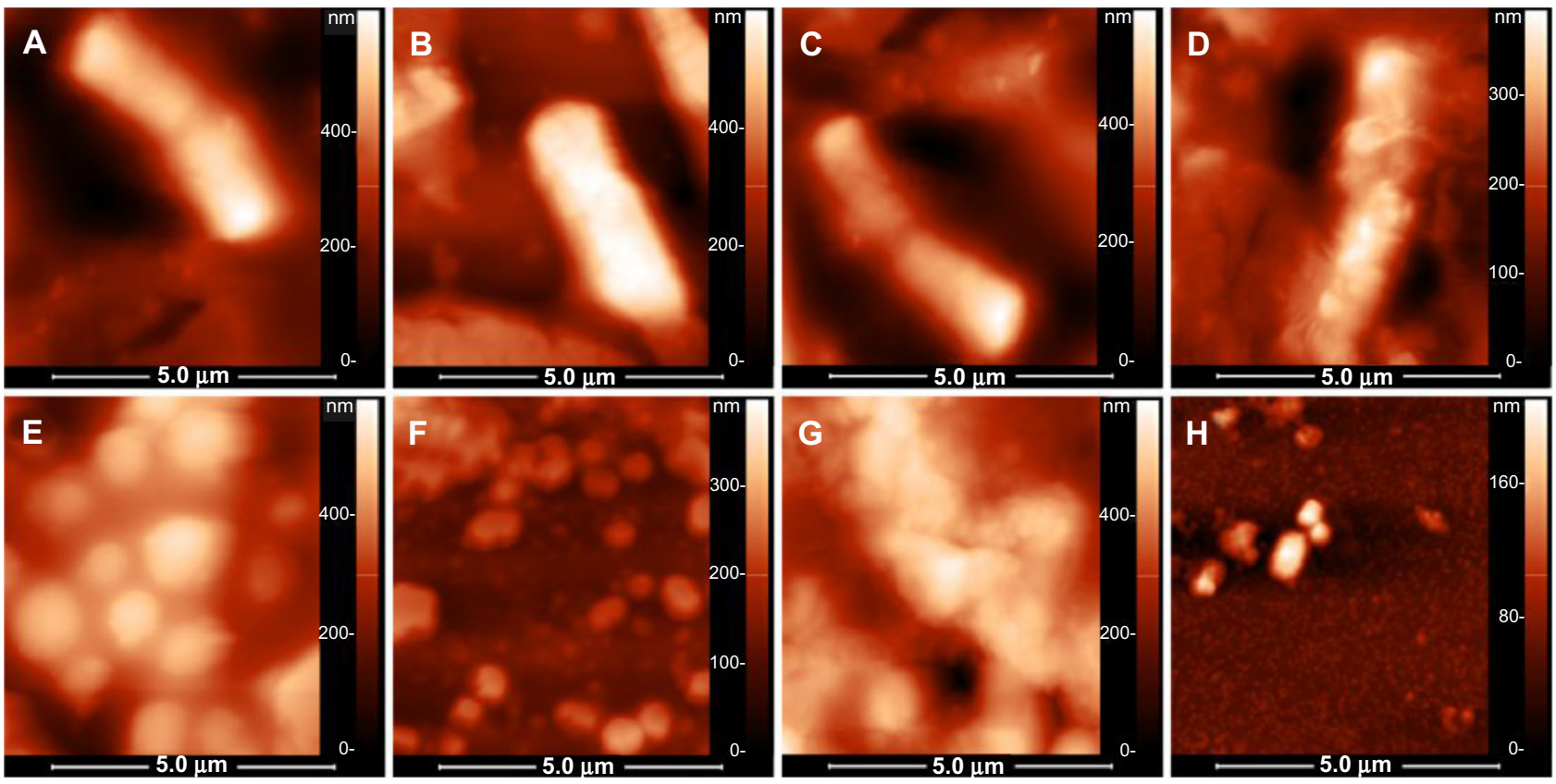

Figure 7 Bacterial morphologies observed by AFM, when treated by SUB-MIC concentrations of the two agents.

Notes: (A-D) Bacillus cereus, (E-H) Staphylococcus aureus. (A and E) No treatment, (B and F) treated with AgNPs, (C and $\mathbf{G})$ treated with cinnamaldehyde, (D and $\mathbf{H})$ treated with slightly reduced concentrations of both agents from best synergy combination.

Abbreviations: AFM, atomic force microscopy; AgNPs, silver nanoparticles; SUB-MIC, sub-minimum inhibitory concentration. 
inhibitory effect remains active with combinations of spice oils, this may allow the development of preservative agents using AgNPs that are completely safe for day-to-day use for foods vulnerable to spoilage. The effectiveness of the combination regimen against spore-forming toxin producing $B$. cereus and $C$. perfringens has been documented for the first time in this study. The extant silver based preservative applications, such as packaging based on coatings of silver, can potentiate antibacterial activities when used in conjunction with combinations of spice oils. Topical applications of AgNPs can also benefit from additions of relevant concentrations of essential oils. Such combinations may also increase the effect of AgNPs use as anti-biofouling agents and other applications. ${ }^{36}$ This direction can also open up avenues for the utilization of the two agents in more systemic contexts for infections caused by multiple drug resistant organisms.

\section{Conclusion}

The study reported here demonstrated the combined antibacterial effect that AgNPs and cinnamaldehyde exhibited against a variety of pathogenic bacterial species. The combination of AgNPs and cinnamaldehyde showed near-synergistic mode of inhibition against the battery of various pathogenic and food spoilage bacteria. Notably, the multi-drug-resistant strain of $V$.fluvialis was inhibited in the combinatorial assays to a much greater extent in comparison to when AgNPs and cinnamaldehyde were used in isolation. Most important is the finding that there was genuine synergy observed against two major spore-forming toxin-producing bacterial pathogens; $B$. cereus and $C$. perfringens. The hemolysis assays which were done to estimate the toxicity of the two agents in the relevant concentrations against human cells did not show any toxic effect. We conclude that a combination of the two antimicrobial agents allows the use of lowered concentrations of both agents in an effective manner, which is well below the toxic threshold for mammalian cells. Taken together, this is the first report documenting the effectiveness of safe levels of AgNPs in combating bacterial pathogens. Detailed toxicological studies will be required to establish the safety of the combination regimen of the two agents. In the long term, more research in this direction will lead to establishment of combination therapy of silver and natural essential oils for food preservation and pathogen control.

\section{Acknowledgments}

This work is supported by National Agricultural Innovation Project (NAIP) grant number C4-30032 of the Indian Council of Agricultural Research (ICAR), Govt. of India to NKN and
RP. SDP was provided with a fellowship by the Council of Industrial Research, India. TKS was provided with a National Doctoral Fellowship by the All India Council of Technical Education (AICTE). SKS is a recipient of a Ministry of Human Resources and Development Fellowship. We thank the Institute Instrumentation facility of the Indian Institute of Technology Roorkee for atomic absorption spectrophotometry, scanning electron microscopy, atomic force microscopy, and transmission electron microscopy facilities.

\section{Disclosure}

The authors declare that they alone are responsible for the content and writing of this paper. The authors report no conflicts of interest in this work.

\section{References}

1. Amalaradjou MA, Bhunia AK. Bioengineered probiotics, a strategic approach to control enteric infections. Bioengineered. Epub January 17, 2013.

2. Atrih A, Foster SJ. Bacterial endospores the ultimate survivors. Int Dairy J. 2002;12(2-3):217-223.

3. Abee T, Groot MN, Tempelaars M, Zwietering M, Moezelaar R, van der Voort M. Germination and outgrowth of spores of Bacillus cereus group members: diversity and role of germinant receptors. Food Microbiol. 2011;28(2):199-208.

4. Andersson A, Ronner U, Granum PE. What problems does the food industry have with the spore-forming pathogens Bacillus cereus and Clostridium perfringens? Int J Food Microbiol. 1995;28(2):145-155.

5. Panacek A, Kvítek L, Prucek R, et al. Silver colloid nanoparticles: Synthesis, characterization, and their antibacterial activity. $J$ Phys Chem B. 2006;110(33):16248-16253.

6. Baker C, Pradhan A, Pakstis L, Pochan DJ, Shah SI. Synthesis and antibacterial properties of silver nanoparticles. J Nanosci Nanotech. 2005;5(2):244-249.

7. Chopra I. The increasing use of silver-based products as antimicrobial agents: a useful development or a cause for concern? J Antimicrob Chemother. 2007;59:587-590.

8. Morones JR, Elechiguerra JL, Camacho A, et al. The bactericidal effect of silver nanoparticles. Nanotechnology. 2005;16:2346-2353.

9. Lok C, Ho C, Chen R, et al. Proteomic analysis of the mode of antibacterial action of silver nanoparticles. J Proteome Res. 2006;5:916-924.

10. Panyala NR, Peña-Méndez EM, Havel J. Silver or silver nanoparticles: A hazardous threat to the environment and human health? $J$ Appl Biomed. 2008;6:117-129.

11. Gill AO, Holley RA. Mechanisms of bactericidal action of cinnamaldehyde against Listeria monocytogenes and of Eugenol against L. monocytogenes and Lactobacillus sakei. Appl Environ Microbiol. 2004; 70(10):5750-5755.

12. López P, Sánchez C, Batlle R, Nerín C. Solid- and vapor-phase antimicrobial activities of six essential oils: Susceptibility of selected food borne bacterial and fungal strains. J Agric Food Chem. 2005;53: 6939-6946.

13. Code of Federal Regulations 21(2008) [webpage on the internet]. United States Food and Drug Administration (USFDA); 2008 [updated April 1, 2013]. Available from: http://www.accessdata.fda.gov/scripts/cdrh/ cfdocs/cfcfr/CFRSearch.cfm?fr=182.60. Accessed August 20, 2013.

14. Hooth MJ, Sills RC, Burka LT, et al. Toxicology and carcinogenesis studies of microencapsulated trans-cinnamaldehyde in rats and mice. Food Chem Toxicol. 2004;42(11):1757-1768.

15. Friedman M, Kozukue N, Harden LA. Cinnamaldehyde content in foods determined by gas chromatography-mass spectrometry. J Agric Food Chem. 2000;48:5702-5709. 
16. Pei RS, Zhou F, Ji BP, Xu J. Evaluation of combined antibacterial effects of eugenol, cinnamaldehyde, thymol, and carvacrol against $E$. coli with an improved method. J Food Sci. 2009;74(7):M379-M383.

17. Brul S, Coote P. Preservative agents in foods: mode of action and microbial resistance mechanisms. Int J Food Microbiol. 1999;50(1-2): $1-17$.

18. Patil SD, Sharma R, Srivastava S, Navani NK, Pathania R. Downregulation of yidC in Escherichia coli by antisense RNA expression results in sensitization to antibacterial essential oils eugenol and carvacrol. PloS One. 2013;8(3):e57370.

19. Boberek JM, Stach J, Good L. Genetic evidence for inhibition of bacterial division protein FtsZ by berberine. PloS One. 2010;5(10):e13745.

20. Ravishankar S, Zhu L, Reyna-Granados J, Law B, Joens L, Friedman M. Carvacrol and cinnamaldehyde inactivate antibiotic-resistant Salmonella enterica in buffer and on celery and oysters. J Food Prot. 2010;73(2):234-240.

21. Singh R, Rajpara N, Tak J, et al. Clinical isolates of Vibrio fluvialis from Kolkata, India, obtained during 2006: plasmids, the qnr gene and a mutation in gyrase A as mechanisms of multidrug resistance. $J$ Med Microbiol. 2012;61(Pt 3):369-374.

22. Munro CH, Smith WE, Garner M, Clarkson J, White PC. Characterization of the surface of a citrate-reduced colloid optimized for use as a substrate for surface-enhanced resonance raman scattering. Langmuir. 1995; 11:3712-3720

23. Clinical and Laboratory Standards Institute. Methods for Dilution Antimicrobial Susceptibility Tests for Bacteria that Grow Aerobically. 8th ed. Wayne: CLSI; 2009.

24. Ruden S, Hilpert K, Berditsch M, Wadhwani P, Ulrich AS. Synergistic interaction between silver nanoparticles and membrane-permeabilizing antimicrobial peptides. Antimicrob Agents Chemother. 2009;53:3538-3540.

25. Climo MW, Patron RL, Archer GL. Combinations of vancomycin and beta-lactams are synergistic against staphylococci with reduced susceptibilities to vancomycin. Antimicrob Agents Chemother. 1999;43: 1747-1753.
26. Bolshakova AV, Kiselyova OI, Filonov AS, Frolova OY, Lyubchenko YL, Yaminsky IV. Comparative studies of bacteria with an atomic force microscopy operating in different modes. Ultramicroscopy. 2001;86(1-2):121-128.

27. ASTM E2524 - 08 standard test method for analysis of hemolytic properties of nanoparticles [webpage on the internet]. West Conshohocken: ASTM International; 2008. Available from: http://www.astm. org/Standards/E2524.htm. Accessed August 20, 2013.

28. Barackman G, Celens S, Hillaert U, et al. Structure-activity relationship of cinnamaldehyde analogs as inhibitors of AI-2 based quorum sensing and their effect on virulence of Vibrio spp. PloS One. 2011;6(1): e16084.

29. Warnke PH, Becker ST, Podschun R, et al. The battle against multiresistant strains: Renaissance of antimicrobial essential oils as a promising force to fight hospital-acquired infections. J Craniomaxillofac Surg 2009;37(7):392-397.

30. Burt S. Essential oils: their antibacterial properties and potential applications in foods - a review. Int J Food Microbiol. 2004;94(3):223-253.

31. Su HL, Chou CC, Hung DJ, et al. The disruption of bacterial membrane integrity through ROS generation induced by nanohybrids of silver and clay. Biomaterials. 2009;30(30):5979-5987.

32. World Health Organization. Guidelines for Drinking-Water Quality. Geneva: WHO; 1996.

33. Silver (CASRN 7440-22-4): Integrated risk information system [webpage on the internet]. United States Environmental Protection Agency (USEPA); 2011 [updated August 9, 2012]. Available from: http:// www.epa.gov/IRIS/subst/0099.htm. Accessed August 20, 2013.

34. Arora S, Jain J, Rajwade JM, Paknikar KM. Cellular responses induced by silver nanoparticles: in vitro studies. Toxicol Lett. 2008;179(2): 93-100.

35. AshaRani PV, Low Kah Mun G, Hande MP, Valiyaveettil S. Cytotoxicity and genotoxicity of silver nanoparticles in human cells. ACS Nano. 2009;3(2):279-290.

36. Seil JT, Webster TJ. Antimicrobial applications of nanotechnology: methods and literature. Int J Nanomedicine. 2012;7:2767-2781.
International Journal of Nanomedicine

\section{Publish your work in this journal}

The International Journal of Nanomedicine is an international, peerreviewed journal focusing on the application of nanotechnology in diagnostics, therapeutics, and drug delivery systems throughout the biomedical field. This journal is indexed on PubMed Central,

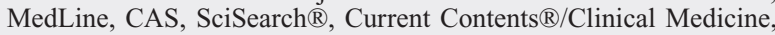

\section{Dovepress}

Journal Citation Reports/Science Edition, EMBase, Scopus and the Elsevier Bibliographic databases. The manuscript management system is completely online and includes a very quick and fair peer-review system, which is all easy to use. Visit http://www.dovepress.com/ testimonials.php to read real quotes from published authors. 